\title{
Descending to the twilight-zone: changes in coral reef fish assemblages along a depth gradient down to $65 \mathrm{~m}$
}

\author{
Eran Brokovich ${ }^{1,2, *}$, Shai Einbinder ${ }^{1,3}$, Nadav Shashar ${ }^{4,5}$, Moshe Kiflawi ${ }^{1,4}$, \\ Salit Kark ${ }^{2}$ \\ ${ }^{1}$ The Interuniversity Institute for Marine Sciences at Eilat (IUI), Marine Twilight-Zone Research \& Exploration (MTRX), \\ PO Box 469, Eilat 88103, Israel \\ ${ }^{2}$ The Biodiversity Research Group, Department of Evolution, Systematics and Ecology, The Institute of Life Sciences, \\ The Hebrew University of Jerusalem, 91904, Israel \\ ${ }^{3}$ Department of Evolution, Systematics and Ecology, The Institute of Life Sciences, The Hebrew \\ University of Jerusalem, 91904, Israel \\ ${ }^{4}$ Faculty of Life Sciences, Ben Gurion University, PO Box 653, Beer-Sheva, 84105, Israel \\ ${ }^{5}$ Eilat Campus, Ben Gurion University, Hatmarim St., Eilat, 88000, Israel
}

\begin{abstract}
In contrast to the abundance of literature on the relationship between fish assemblages and habitat structure in the upper $30 \mathrm{~m}$ of coral reefs, the deeper $(>40 \mathrm{~m})$ parts of coral reefs are rarely studied. We examined changes in reef fish diversity and habitat structure along an increasing depth gradient, including the unknown deep reef. We ran visual and video transects along a substantial depth gradient $(0$ to $65 \mathrm{~m}$ ) in the northern Red Sea and extended the known depth distribution for 48 reef species. We found a change in assemblage composition highly correlated to both the depth gradient and a reduction in the abundance of branching corals with depth. The number of reef fish species declined with depth and we also measured a high species turnover as measured by beta diversity $\left(\beta_{\mathrm{t}}, \beta_{\mathrm{w}}\right)$ in the deep reef. This pattern is mainly due to the replacement of the abundant damselfishes in the shallow reef, which prey on zooplankton, by zooplanktivorous sea basses and wrasses in the deep reef. The steep reduction in branching corals, which most damselfishes use for cover, may be the main factor contributing to this change. We found a peak in species richness (alpha diversity) at $30 \mathrm{~m}$, a peak in $\beta_{\mathrm{w}}$ at 50 to $65 \mathrm{~m}$, and peaks in $\beta_{\mathrm{t}}$ at 30 to $50 \mathrm{~m}$ and 50 to $65 \mathrm{~m}$. The $30 \mathrm{~m}$ depth stratum shows species of both shallow and deep assemblages generating a transition zone with characters of both deep and shallow habitats. The fish assemblage continues to change with depth, and future research will determine if there exists a depth threshold at which the assemblage will stabilize.
\end{abstract}

KEY WORDS: Depth gradient · Deep reef fish · Gulf of Aqaba · Red Sea · Twilight zone

\section{INTRODUCTION}

Tropical and subtropical coral reefs are among the most diverse biological communities on earth (Bellwood \& Hughes 2001, Fishelson 2003). Much of the spatial variation in the structure of local fish communities can be explained by depth and related gradients (McGehee 1994, Friedlander \& Parrish 1998, ArreolaRobles \& Elorduy-Garay 2002, Donaldson 2002, Broko- vich et al. 2006). Depth gradients are important agents structuring coral reefs due to the substantial changes in both physical and biotic factors occurring over relatively short depths. Habitat structure and its related abiotic parameters are also considered important in shaping the processes that affect the composition of coral reef fish species, families and trophic groups (Carpenter et al. 1981, Sheppard et al. 1992, Meekan et al. 1995, Friedlander \& Parrish 1998, Nanami \& 
Nishihira 2002). Habitat structure and related abiotic parameters have been shown to be some of the main factors structuring fish communities (McGehee 1994, Lara \& Gonzalez 1998, Wantiez \& Chauvet 2003, Brokovich et al. 2006). In the context of depth gradients, decreased light levels may hinder the ability of mobile organisms to forage (Rickel \& Genin 2005), can decrease algae growth rates (Russ 2003) and can modify coral assemblages and resulting habitat structure. Srinivasan (2003) demonstrated that the distribution of some coral reef fishes over different depths is established at and/or soon after settlement, and suggests that factors associated with depth may explain differences in settlement, growth and survival, and warrant further investigation.

While scuba diving has enabled researchers to study these patterns in shallow coral reefs with relative ease and safety, deep habitats are still rarely studied in detail because of decreasing bottom times with depth, and the inherent risks of breathing elevated partial pressures of oxygen and nitrogen. The literature now includes a number of studies that use remote video, submersibles and mixed gas diving to study reef communities of fishes, invertebrates and plants in both tropical and subtropical waters deeper than $30 \mathrm{~m}$ (Fricke \& Schumacher 1983, Colin et al. 1986, Fricke 1996, Aponte \& Ballantine 2001, Cappo et al. 2004, Feitoza et al. 2005). Deep scuba diving has become safer through the use of special gas mixtures (Trimix) thus enabling deeper and longer research. This enables the use of the same research methods in both deep and shallow reefs, which facilitates direct comparison.

The Red Sea is considered a threatened biodiversity hotspot with high species richness and endemism (Roberts et al. 2002, Mora et al. 2003). The Gulf of Aqaba, located on the northern edge of the Indo-West Pacific province (northern Red Sea, Fig. 1) is a distinct biogeographical region in the Red Sea (Sheppard et al. 1992) in which coral, fish and other organisms create distinct assemblages (Ormond \& Edwards 1987, Sheppard et al. 1992). Limited observations revealed that the coral reefs in the northern Gulf of Aqaba extend to depths of 100 to $150 \mathrm{~m}$ (Fricke \& Schumacher 1983). Hence, the current data on coral reefs in the area (as in most of the world), limited mostly to 0 to $30 \mathrm{~m}$, reflects only a small part of the total reef area (Ben-Tuvia et al. 1983, Rilov \& Benayahu 1998, 2000, Brokovich 2001, Khalaf \& Kochzius 2002, Brokovich et al. 2006).

The aims of the present study were 2-fold. First, to examine the unknown fish assemblages of the deep reef and how they relate to changes in depth and habitat structure. Second, to examine the distinctness of shallow and deep assemblages and the transition between them. Specifically, we sampled and analysed fish spe- cies distribution along a depth gradient between 0 and $65 \mathrm{~m}$. We tested the following parameters for change along the depth gradient: (1) habitat variables, including the amount of hard substratum and the percentage of live sessile fauna, branching corals and branching corals within live fauna; (2) fish assemblage structure (species and families composition and abundance); (3) fish abundance; (4) species richness ( $\alpha$ diversity) of fish within each depth; and (5) the rate of fish turnover between adjacent depths, also known as beta diversity ( $\beta$ ). We also tested if the fish assemblage structure and abundance changed with habitat variables.

\section{MATERIALS AND METHODS}

Study sites. We chose 3 sites along the western shores of the northern Gulf of Aqaba to represent the deep reef habitats (Fig. 1). Site 1, The Dekel Beach (Dekel), consists of a sandy slope with scarce corals from 0 to $18 \mathrm{~m}$ changing to a relatively well-developed reef which extends to at least $60 \mathrm{~m}$. The second site, The Japanese Gardens (JG), is an area with a welldeveloped reef extending from shallow water to at least $55 \mathrm{~m}$. The third site, located offshore from The Interuniversity Institute beach (IUI), is characterized by an extensive, continuous deep reef to $68 \mathrm{~m}$. Characteristics of the shallow portion of these habitats, including topography and the coral community (Loya \& Slobodkin 1971, Mergner 1971) and structural indices of

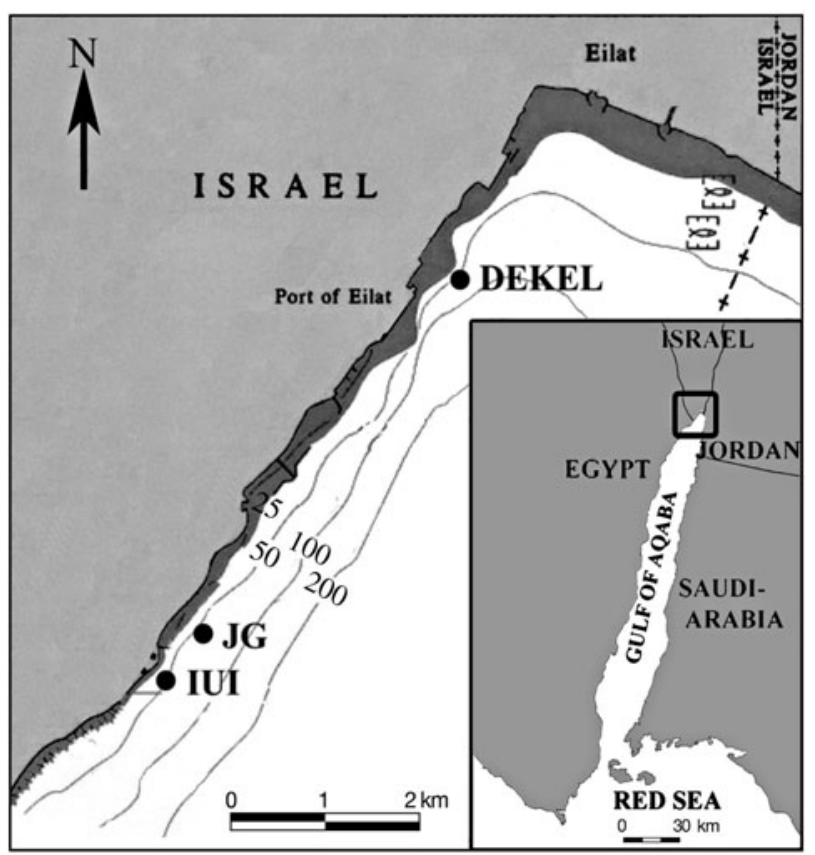

Fig. 1. Study area and sampling sites. IUI: Interuniversity Institute; JG: Japanese Gardens; DEKEL: Dekel beach 
shallow habitats (Brokovich \& Baranes 2005, Brokovich et al. 2006) were covered in previous studies. The Gulf of Aqaba, as part of the Red Sea, has a temperature regime with a minimum winter temperature of approximately $21^{\circ} \mathrm{C}$ along the entire depth gradient (Lindell \& Post 1995). In summer there is weak stratification and about $1.5^{\circ} \mathrm{C}$ difference between 6 and $40 \mathrm{~m}$ (Rosenfeld et al. 2003).

Sampling design. We (E.B. and S.E.) used advanced technical diving techniques (Trimix scuba diving) to directly record and study the fish and corals along a depth gradient from 5 to $65 \mathrm{~m}$. Sampling took place between December 2003 and April 2006. At each of the 3 sites we conducted visual censuses of the fish community using belt transects of $25 \times 2 \mathrm{~m}$ at 5 different depths $(5,10,30,50$ and $65 \mathrm{~m})$. As 20 min was our maximum bottom time at $65 \mathrm{~m}$, we limited all transects to this duration to maintain the same sampling effort in all depths. The short bottom time also dictated the choice of relatively short $(25 \mathrm{~m})$ transects. The number of transects at each site and depth was limited by the amount of continuous reef. For example, at Dekel there was no continuous reef at 5 and $10 \mathrm{~m}$ and only a limited area of continuous reef at $65 \mathrm{~m}$; therefore, we ran 3 transects at $30 \mathrm{~m}, 4$ transects at $50 \mathrm{~m}$ and 1 transect at $65 \mathrm{~m}$. At JG we ran 3 transects at $5 \mathrm{~m}, 3$ at $10 \mathrm{~m}, 3$ at $30 \mathrm{~m}, 4$ at $50 \mathrm{~m}$ and none at $65 \mathrm{~m}$. At IUI we ran 4 transects at $5 \mathrm{~m}, 3$ at $10 \mathrm{~m}, 4$ at $30 \mathrm{~m}, 4$ at $50 \mathrm{~m}$ and 6 at $65 \mathrm{~m}$. This pattern resulted in an incomplete ANOVA design. All fish identifications and abundance evaluations were recorded on plastic slates. Only fish that passed in front of the diver were recorded, and a whole school was counted if one of its fishes crossed the transect, following Bortone et al. (1986). Fish were identified, with few exceptions, to species level. Fish identification was based on Randall (1983, 1995), Randall et al. (1990), Debelius (1993, 1998) and Khalaf \& Disi (1997). Nomenclature followed Fishbase (Froese \& Pauly 2007). A few unidentified fishes were photographed and identified later in the lab. To expand our species list and to study the depth distribution of the different species more accurately, we ran longitudinal transects (perpendicular to the beach) from $65 \mathrm{~m}$ to $5 \mathrm{~m}$ at the end of all the $65 \mathrm{~m}$ dives and noted the depth of the first appearance of different species. Substrate and cover types were video-recorded (Sony DCR-VX1000 with Gates housing) using standard $10 \mathrm{~m}$ line transects (Loya \& Slobodkin 1971) at each of the 5 depths from 5 to $65 \mathrm{~m}$. Video transects were done on a separate measuring tape so as not to interfere with the fish census. All $1000 \mathrm{~cm}$ of the substratum transect were analyzed in the lab. Each substrate and cover type directly under the line was measured to the nearest centimeter. The categories used were sand, coral rubble and small stones $(<10 \mathrm{~cm})$, rock, dead corals and cover by live sessile fauna (mainly corals which were labelled massive or branching, but also sponges, corallimorpharians, sea anemones, etc., which were all grouped with corals as 'live cover'). All of the categories except sand create an available substrate for reef organisms and were thus grouped as 'hard cover'. Depths of 5 and $10 \mathrm{~m}$ were defined as shallow depths, $30 \mathrm{~m}$ as mid depth and 50 and $65 \mathrm{~m}$ as the deep reef.

Data analysis. To examine the change in habitat parameters with depth we correlated depth to the amount of hard substratum, the percentage of live cover, the percentage of branching corals and the percentage of branching corals within live cover (habitat variables). We used both univariate and multivariate approaches to examine changes in fish assemblage structure. These included the analysis of species composition, species richness ( $\alpha$ diversity) and turnover ( $\beta$ diversity), and family-level changes in abundance.

Species composition: To test for changes in assemblage structure between depths we used nonmetric Multi Dimensional Scaling (nMDS, following Clarke 1993). We used the Bray-Curtis coefficient of similarity to analyze both presence/absence and abundance data utilizing the Primer ${ }^{\mathrm{TM}}$ computer program (v.5.2.2, Primer-E). Abundance was fourth-root transformed to reduce the dominance of very large fish schools (Clarke 1993). To test for pairwise differences in assemblage structure between depths and among sites we used a 2-way analysis of similarities (ANOSIM) routine using Primer ${ }^{\mathrm{TM}}$. For the pairwise analysis we used a Bonferroni adjustment of significance levels (Statistica, StatSoft). To test for a change in assemblages along gradients of both depth and habitat variables we used a Canonical Analysis of Principal Coordinates (CAP, following Anderson \& Willis 2003). CAP is a 2-step process combining 2 existing multivariate techniques: principal coordinate analysis (PCO) followed by a canonical correlation analysis (CCorA) on unscaled orthonormal PCO axes, with $m$ being the number of axes that minimizes the residual error. CAP analysis was conducted with the cap.exe computer program (Anderson 2002), using the Bray-Curtis coefficient of dissimilarity in fourth-root transformed abundance. The contribution of the various habitat variables to the first CAP axis was inferred from its correlation to the original variables, and tested using both the Root and Trace statistics with 9999 permutations (Anderson \& Robinson 2003). To identify those species that contribute most to the multivariate pattern, we isolated those species which had a strong correlation $(>0.5)$ between the original data and the first CAP axis. Correlations of species with canonical axes provide a good indication of which species should be investigated in more detail with univariate analysis (Anderson \& Willis 2003). 
$\boldsymbol{\beta}$ diversity: We examined the change in species richness along the depth gradient by calculating $\beta$ diversity between depths. We chose to use two $\beta$ diversity indices that highlight 2 different aspects of species turnover: (1) $\beta_{\mathrm{t}}$ an improvement of the most common index $\beta_{\mathrm{w}}$, which depends largely on the number of shared species (Wilson \& Shmida 1984, Koleff et al. 2003); and (2) $\beta_{\text {sim, }}$ which depends largely on loss and gain of species and was found to perform better than other measures in its group (Lennon et al. 2001, Koleff et al. 2003, Mena \& Vazquez-Dominguez 2005). We calculated $\beta$ diversity indices between adjacent depths $(5-10,10-30,30-50$ and $50-65 \mathrm{~m})$ across all the sites: each transect was measured for $\beta$ diversity against all transects in adjacent depths. We compared the average $\beta$ diversity between adjacent depths using a Kruskal-Wallis non-parametric ANOVA due to heterogeneity of variance. We used Kruskal-Wallis multiple comparisons of mean ranks for post hoc tests.

$\boldsymbol{\alpha}$ diversity: The effect of depth on $\alpha$ diversity was evaluated using rarefaction curves to control for differences in sampling effort (due to different number of transects in each depth, as well as differences in total fish abundance). We generated individual-based accu- mulation curves using EstimateS (Colwell 2005), with the number of sampled individuals as the rarefied variable following Colwell \& Coddington (1994), Gotelli \& Colwell (2001) and Colwell et al. (2004a).

Abundance: We examined family-level representation at each depth by calculating the abundance of fishes belonging to each family at each transect and then averaging transects per depth strata. We also examined the relationships between fish abundance and each of the abiotic variables tested (depth, hard cover, live cover and branching coral abundance).

\section{RESULTS}

Overall, in 42 transects, we recorded 8220 individuals from 159 species and 33 families. We extended the reported depth limits (Khalaf \& Disi 1997, Lieske \& Myers 2004, Froese \& Pauly 2007) of 48 fish species by $10 \mathrm{~m}$ or more and for some fish by at least $40 \mathrm{~m}$ (Appendix 1, available at www.int-res.com/articles/ suppl/m371p253_app.pdf). The general topography of the deep reef was flatter than the deep reef (Fig. 2). The percentage of hard cover dropped from $80 \%$ in


Fig. 2. Shallow habitat at $5 \mathrm{~m}$ (A), mid depth at $30 \mathrm{~m} \mathrm{(B)}$ and the deep reef at $60 \mathrm{~m}$ with typical coral gravel (C) and flat coral colonies (D) 
Table 1. ANOSIM results. Analysis of pairwise tests for species similarities between each 2 depths (presence/absence data). Accepted significance level after Bonferroni correction $\mathrm{p}<0.005$ (0.05 divided by 10 tests)

\begin{tabular}{|lcc|}
\hline Depth groups & \multicolumn{2}{c|}{$\begin{array}{c}\text { Species similarities between all depths } \\
\text { R }\end{array}$} \\
\hline 5,10 & 0.546 & 0.017 \\
5,30 & 0.943 & 0.003 \\
5,50 & 1.000 & 0.001 \\
5,65 & 0.966 & 0.005 \\
10,30 & 0.881 & 0.003 \\
10,50 & 0.931 & 0.001 \\
10,65 & 0.929 & 0.012 \\
30,50 & 0.713 & 0.0001 \\
30,65 & 0.854 & 0.001 \\
50,65 & 0.272 & 0.06 \\
\hline
\end{tabular}

$5 \mathrm{~m}$ to about $45 \%$ in $10 \mathrm{~m}$ and then increased 2-fold with depth to almost $100 \%$ in $65 \mathrm{~m}$. Cover by live sessile fauna (live cover) was relatively constant at approximately $20 \%$. Branching coral abundance decreased with depth $(r=-0.83, p=0.001)$. The proportion of branching coral to live cover and hard substrate also decreased with depth $(\mathrm{r}=-0.90, \mathrm{p}<0.001$; $\mathrm{r}=$ $-0.85, \mathrm{p}<0.001$ respectively) (Fig. 3).

\section{Species composition}

The manner by which species composition changed with depth did not differ between the 3 study sites (2-way ANOSIM, Depth $\times$ Sites, $\mathrm{R}=0.41 \mathrm{p}<0.01$ ). Hence, we pooled the data across sites prior to testing for pairwise differences among depths. Fish assemblage composition changed with depth, both in terms of species presence/absence (ANOSIM, R $=0.73 \mathrm{p}<$ 0.0001 , ) and abundance $(\mathrm{R}=0.743, \mathrm{p}<0.001)$ (Fig. $4 \mathrm{~A})$.
ANOSIM tests showed significant pairwise differences between depths of $65 \mathrm{~m}$ and $\leq 30 \mathrm{~m}$, and also between 5 and $50 \mathrm{~m}$ (Table 1). The CAP used 5 PCO axes which explained $\sim 62 \%$ of the variation in the original species data (Fig. 4B). Eigenvalues of canonical axes 1 and 2 were 0.985 and 0.85 respectively. CAP axis 1 was highly correlated with depth, percentage of branching corals and the ratio of branching corals to live cover $(0.97,-0.78,-0.88$ respectively) (Fig. $4 \mathrm{C})$. We found somewhat lower correlations between CAP axes 1 and 2 to the percentage of hard cover (0.55 and -0.48 respectively) (Fig. 4C). The fish assemblage changed significantly along the first CAP axis (Trace statistic = 2.4, $\mathrm{p}=0.0001$ ). Several fish including Cirrhilabrus blatteus, Chromis pelloura, and Cirrhilabrus rubriventralis had high positive correlations ( $>0.5$ ) with the first CAP axis (typical deep reef species) and another 14 species had high negative correlations with the first CAP axis (typical shallow water species) (Table 2, Fig. 4C).

\section{$\beta$ diversity}

The rate of species turnover increased with depth. $\beta_{\mathrm{t}}$ increased by $\sim 30 \%$ between each adjacent depth up to about 0.7 at $30-50 \mathrm{~m}$. $\beta_{\text {sim }}$ also increased with depth up to about 0.6 , but there was no difference in its value between $10-30$ and 30-50 m (Fig. 5). Of the 59 species sampled below $30 \mathrm{~m}, 15$ were found exclusively there (Appendix 1) and 4, including Pseudanthias fasciatus, Chromis pelloura, Bodianus opercularis and Cirrhilabrus blatteus, are not known from the shallow and mid depths. Of these 4 unique deep species $P$. fasciatus and $B$. opercularis were encountered only once during this research and $C$. pelloura is suggested as vulnerable by IUCN criteria (Kochzius 2003).
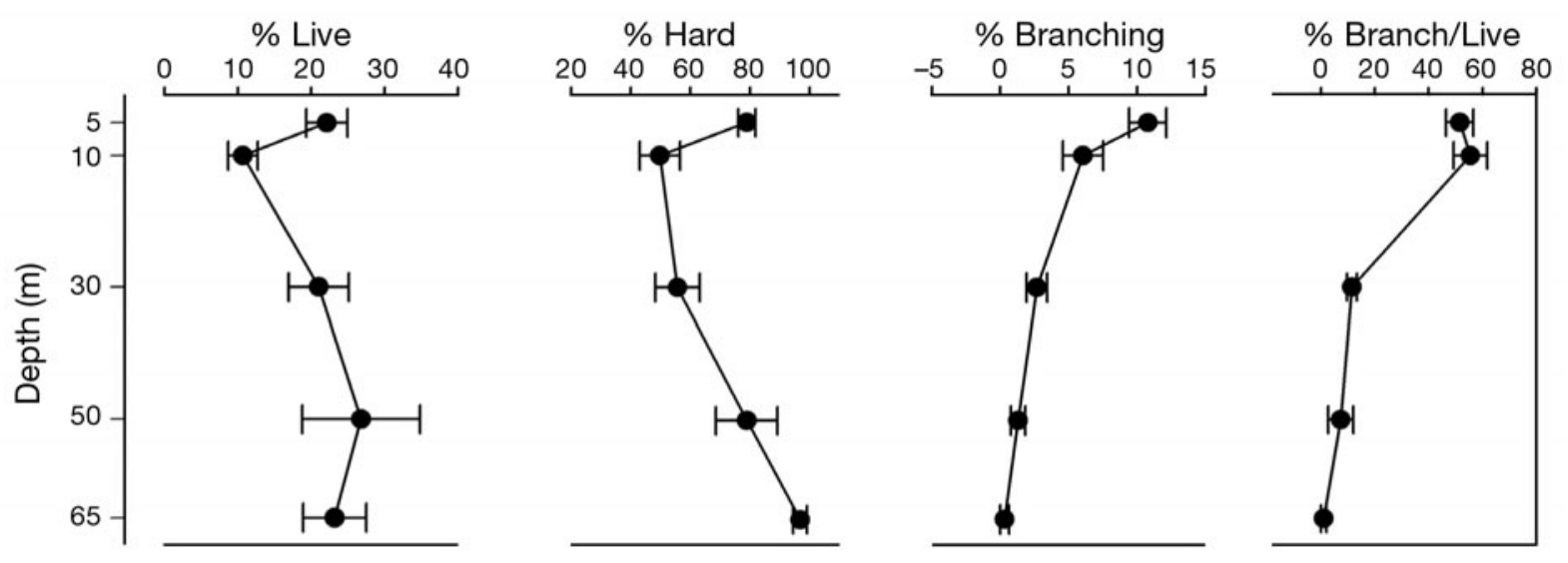

Fig. 3. Substratum characteristics along the depth gradient. Horizontal lines represent SD. From left: average relative abundances of live cover, hard cover and branching and the average abundance of branching corals from total live cover 
Table 2. Species with highest contribution to segregation along first CAP axis and their average abundance at each depth. Those with a positive correlation are identified with the deeper habitats

\begin{tabular}{|lrrrrrrr|}
\hline Species & $\begin{array}{c}\text { Correlation } \\
\text { to CAP } 1\end{array}$ & $5 \mathrm{~m}$ & $10 \mathrm{~m}$ & $30 \mathrm{~m}$ & $50 \mathrm{~m}$ & $65 \mathrm{~m}$ \\
\hline Cirrhilabrus blatteus & 0.728 & 0.00 & 0.00 & 0.00 & 9.00 & 42.00 \\
Chromis pelloura & 0.557 & 0.00 & 0.00 & 0.00 & 3.54 & 6.71 \\
Cirrhilabrus rubriventralis & 0.524 & 0.00 & 0.00 & 0.50 & 26.01 & 2.86 \\
Amphiprion bicinctus & -0.515 & 1.29 & 0.67 & 0.60 & 0.08 & 0.14 \\
Eviota prasites & -0.518 & 2.29 & 14.92 & 15.00 & 10.00 & 0.00 \\
Thalassoma sp. & -0.523 & 4.86 & 0.00 & 0.00 & 0.00 & 0.00 \\
Zebrasoma xanthurum & -0.592 & 1.71 & 0.50 & 0.40 & 0.00 & 0.00 \\
Chromis viridis & -0.609 & 8.43 & 59.00 & 0.00 & 0.00 & 0.00 \\
Pseudanthias squamipinnis & -0.617 & 39.29 & 18.50 & 4.10 & 0.00 & 0.00 \\
Acanthurus nigrofuscus & -0.624 & 2.00 & 0.67 & 0.00 & 0.00 & 0.00 \\
Dascyllus aruanus & -0.626 & 2.43 & 1.92 & 0.00 & 0.00 & 0.00 \\
Trimma avidori & -0.756 & 2.29 & 2.67 & 0.40 & 0.00 & 0.00 \\
Eviota guttata & -0.772 & 6.57 & 3.83 & 0.40 & 0.00 & 0.00 \\
Gnatholepis anjerensis & -0.786 & 4.29 & 7.67 & 1.50 & 0.50 & 0.00 \\
Pseudochromis olivaceus & -0.793 & 6.00 & 4.83 & 0.20 & 0.08 & 0.00 \\
Gobiodon reticulatus & -0.823 & 6.00 & 2.67 & 1.70 & 0.00 & 0.00 \\
Dascyllus marginatus & -0.894 & 27.29 & 31.08 & 9.40 & 0.00 & 0.00 \\
& & & & & & & \\
\hline
\end{tabular}

$\alpha$ diversity

The accumulated number of species was lower in the deep reef, with half as many species as in shallow and mid depths (Fig. 6). The mid depth had the highest species richness and incorporated $63 \%$ of the species sampled in all depths (Fig. 6).

\section{Abundance}

At the family level, we found a transition from a damselfish (Pomacentridae) and goby (Gobiidae) dominated community to a wrasse (Labridae) and sea bass (Serranidae) dominated community (Fig. 7). The 5 most abundant families represent more than $85 \%$ of the total fish abundance in each depth as well as $\sim 54 \%$ of all the species (Tables $3 \& 4$ ).
A
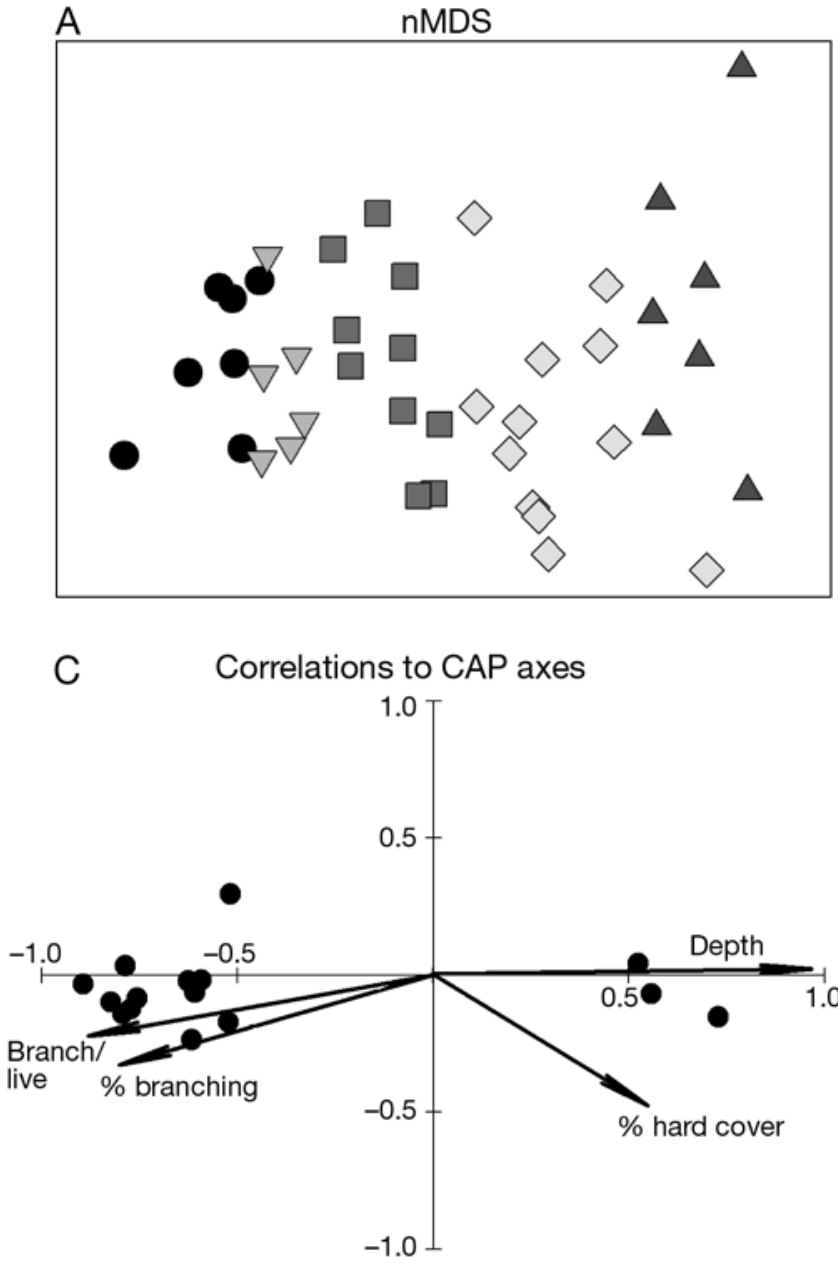

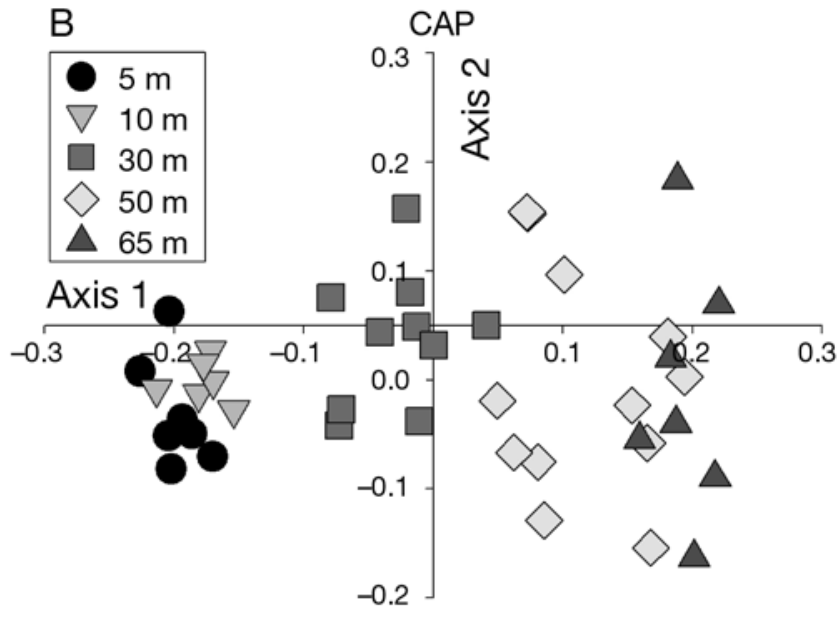

Fig. 4. Multivariate analysis. (A) Fish assemblages represented by unconstrained, nonparametric Multi Dimensional Scaling (nMDS); stress level is 0.15. (B) Fish assemblages represented by a constrained Canonical correlation Analysis of Principal coordinates (CAP). (C) Correlations; (๑) most influential species on CAP axes $1 \times 2$ (17 species with correlation coeffficients $>0.5$ ); (arrows, variable names): correlations of depth and habitat variables with the CAP axes 


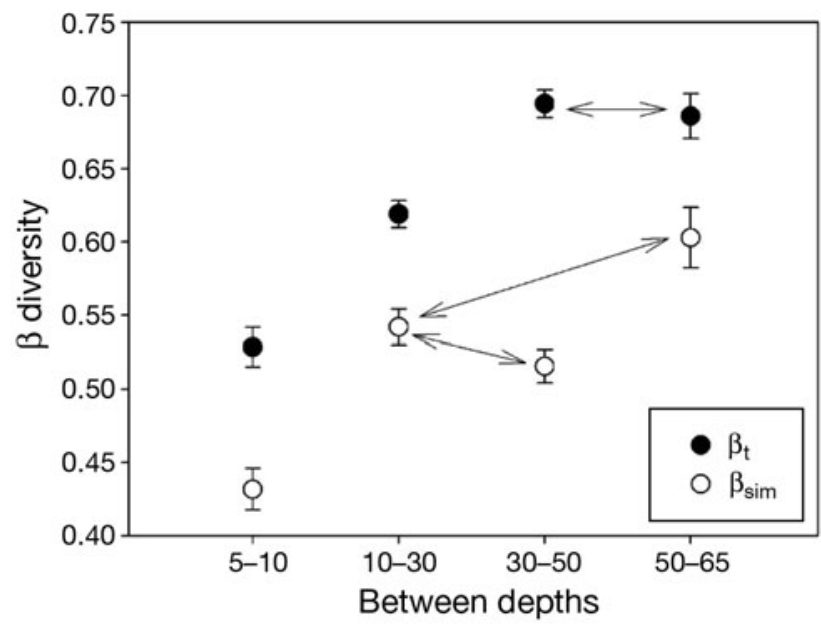

Fig. 5. $\beta_{\mathrm{t}}$ and $\beta_{\mathrm{sim}}$ values between each 2 adjacent depths $\pm \mathrm{SE}$ (e.g. 5-10 means beta diversity between $5 \mathrm{~m}$ transects and $10 \mathrm{~m}$ transects). Beta values connected by arrows show no significant difference

Total fish abundance did not change with depth $(1$-way ANOVA, p < 0.88) nor did it correlate with any of the measured habitat factors.

\section{DISCUSSION}

The results of this work suggest that the fish assemblage structure in the northern Gulf of Aqaba changes gradually as depth increases. The deep coral reef fish community in the northern Red Sea is distinctive and includes several endemic species not found elsewhere. In addition, the abundances of the different families in the deep reef is different compared with the shallow reef. We show that the mid depth $(30 \mathrm{~m})$ assemblage is

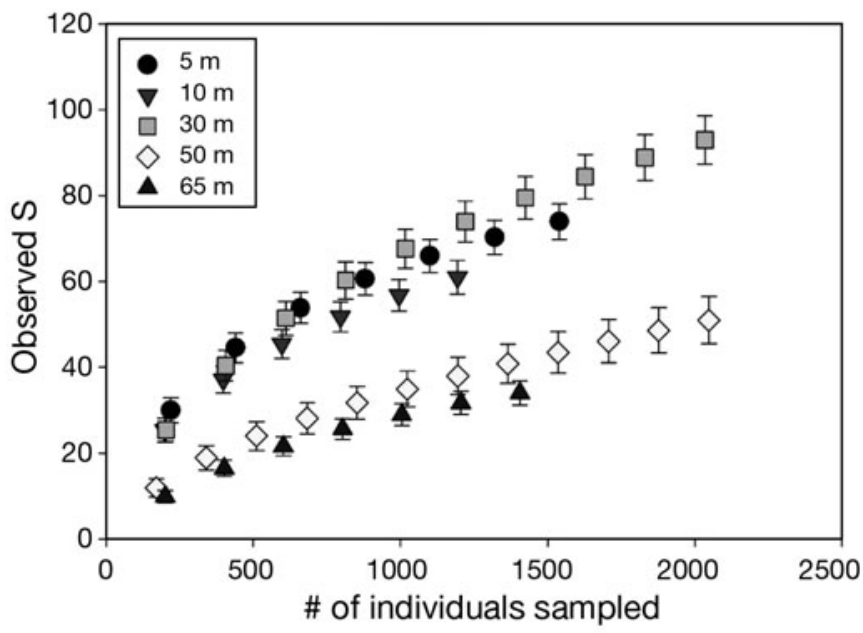

Fig. 6. Accumulated number of species in different depths. Vertical lines: analytical SD the richest in species numbers followed by a steep decline in the deep reef. Notwithstanding the decline in species number, it is interesting that total fish abundance remains relatively similar along the entire depth gradient.

Brokovich (2001), studying Eilat's shallow habitats, and others studying shallow water elsewhere (Grigg 1994, Chabanet et al. 1997, Lewis 1997, Jones \& Syms 1998, Lara \& Gonzalez 1998), have shown that the number of species and their abundance depend mainly on the habitat structural complexity and heterogeneity. Here, we found that the hard substrate cover in the deeper reefs of Eilat reaches almost $100 \%$. However, the most pronounced habitat variable correlating with the fish assemblage structure is a depth-related decline in the relative abundance of branching corals in the live cover. This, together with a reduction in high relief topography in general (pers. obs.) results in fewer hiding places for fish and the disappearance of species that live in obligatory symbioses with branching corals. Also, less sand patches lead to a more homogenous cover and may have a negative effect on species numbers. It is likely that a number of additional abiotic and biotic factors, beside depth and habitat structure, are also responsible for the decrease in fish diversity at the deep reef (e.g. light levels, competition, predation, larval supply, behaviour). We found a shift in family composition from the abundant and diverse damselfishes (Pomacentridae) in the shallow water to sea basses (Serranidae) and wrasses (Labridae) in the deep reef. Pyle (2000) showed that in deep water $(>90 \mathrm{~m})$ the latter 2 belong to the most species-rich families. As Ohman et al. (1997) showed, damselfishes are closely associated with branching corals and use them for shelter. The decline in the amount of branching corals with depth, together with a more flattened coral morpho-



Fig. 7. Relative abundance of the 5 most common families along the depth gradient. SE given in Table 3 
Table 3. Average abundance $( \pm \mathrm{SE})$ of the 15 most abundant families at each depth. Families are listed in order of decreasing abundance at $5 \mathrm{~m}$

\begin{tabular}{|c|c|c|c|c|c|}
\hline \multirow{2}{*}{ Family } & \multicolumn{5}{|c|}{ Average abundance at each depth } \\
\hline & $5 \mathrm{~m}$ & $10 \mathrm{~m}$ & $30 \mathrm{~m}$ & $50 \mathrm{~m}$ & $65 \mathrm{~m}$ \\
\hline Pomacentridae & $73.7 \pm 17$ & $105.8 \pm 46.5$ & $76.55 \pm 30.8$ & $7.8 \pm 2.7$ & $8 \pm 3.2$ \\
\hline Labridae & $47.9 \pm 22.3$ & $9.7 \pm 2.4$ & $56.6 \pm 19.2$ & $118.2 \pm 54.2$ & $53.6 \pm 9.3$ \\
\hline Serranidae & $41.3 \pm 17$ & $20.8 \pm 11$ & $11.4 \pm 7.8$ & $1.9 \pm 1.2$ & $122.1 \pm 77.3$ \\
\hline Gobiidae & $27.4 \pm 2.9$ & $42.9 \pm 9.8$ & $32.2 \pm 4.1$ & $29.4 \pm 14.1$ & $4 \pm 2.7$ \\
\hline Pseudochromidae & $6.6 \pm 1.4$ & $7.7 \pm 1.5$ & $6.7 \pm 1.9$ & $3 \pm 1.5$ & $0.4 \pm 0.2$ \\
\hline Chaetodontidae & $4.9 \pm 1.9$ & $2.3 \pm 0.7$ & $2.8 \pm 0.9$ & $1 \pm 0.4$ & $0.1 \pm 0.1$ \\
\hline Acanthuridae & $4.7 \pm 1.6$ & $1.2 \pm 0.6$ & $0.5 \pm 0.2$ & $0 \pm 0$ & $0 \pm 0$ \\
\hline Scaridae & $2.1 \pm 0.5$ & $1.5 \pm 1$ & $0.6 \pm 0.2$ & $0.3 \pm 0.2$ & $1 \pm 0.4$ \\
\hline Siganidae & $2 \pm 1.7$ & $0.2 \pm 0.2$ & $0.1 \pm 0.1$ & $0.1 \pm 0.1$ & $0 \pm 0$ \\
\hline Blenniidae & $1.7 \pm 0.9$ & $1 \pm 0.4$ & $1.4 \pm 0.6$ & $0.1 \pm 0.1$ & $0.8 \pm 0.4$ \\
\hline Apogonidae & $1.4 \pm 1.1$ & $1 \pm 0.4$ & $2 \pm 0.7$ & $2.5 \pm 2.1$ & $0 \pm 0$ \\
\hline Syngnathidae & $1 \pm 0.6$ & $0.6 \pm 0.3$ & $0.2 \pm 0.2$ & $0 \pm 0$ & $0 \pm 0$ \\
\hline Mullidae & $0.9 \pm 0.3$ & $0.7 \pm 0.5$ & $1.3 \pm 0.6$ & $2.2 \pm 1$ & $0.6 \pm 0.4$ \\
\hline Scorpaenidae & $0.9 \pm 0.6$ & $0.8 \pm 0.4$ & $1.1 \pm 0.4$ & $0.6 \pm 0.3$ & $0.2 \pm 0.1$ \\
\hline Holocentridae & $0.3 \pm 0.2$ & $0 \pm 0$ & $0.5 \pm 0.3$ & $0 \pm 0$ & $0 \pm 0$ \\
\hline
\end{tabular}

logy (Mass et al. 2007) which hinders the usage of the corals for shelter, may well be a major factor contributing to the change in damselfish dominance. Further, sea basses and wrasses reside within the reef itself rather than in certain types of corals. The majority of damselfishes in shallow waters are zooplankti-

Table 4. Number of species per depth for each family and the total number of species per family

\begin{tabular}{|lcccccc}
\hline & \multicolumn{7}{c}{ Family } & \multicolumn{7}{c}{ Depth } & & & Total \\
\cline { 2 - 6 } & $5 \mathrm{~m}$ & $10 \mathrm{~m}$ & $30 \mathrm{~m}$ & $50 \mathrm{~m}$ & $65 \mathrm{~m}$ & species \\
\hline Labridae & 12 & 10 & 13 & 8 & 7 & 22 \\
Pomacentridae & 10 & 8 & 7 & 5 & 3 & 13 \\
Gobiidae & 11 & 13 & 19 & 9 & 4 & 25 \\
Serranidae & 3 & 5 & 7 & 4 & 4 & 9 \\
Pseudochromidae & 2 & 3 & 5 & 5 & 1 & 6 \\
Pomacanthidae & 1 & 1 & 2 & 2 & 2 & 3 \\
Chaetodontidae & 3 & 3 & 4 & 2 & 1 & 5 \\
Apogonidae & 2 & 1 & 4 & 1 & 0 & 4 \\
Mullidae & 2 & 2 & 2 & 2 & 1 & 3 \\
Blenniidae & 2 & 2 & 4 & 1 & 1 & 6 \\
Scaridae & 5 & 2 & 6 & 3 & 3 & 8 \\
Scorpaenidae & 1 & 2 & 4 & 1 & 1 & 4 \\
Acanthuridae & 3 & 2 & 2 & 0 & 0 & 3 \\
Siganidae & 3 & 1 & 1 & 1 & 0 & 3 \\
Synodontidae & 2 & 1 & 2 & 1 & 1 & 2 \\
Balistidae & 3 & 2 & 1 & 1 & 1 & 3 \\
Syngnathidae & 2 & 1 & 1 & 0 & 0 & 2 \\
Muraenidae & 2 & 1 & 2 & 1 & 0 & 3 \\
Tetraodontidae & 1 & 1 & 0 & 1 & 1 & 2 \\
Ostraciidae & 0 & 0 & 2 & 0 & 1 & 2 \\
Tripterygiidae & 1 & 0 & 1 & 0 & 0 & 2 \\
Ephippidae & 0 & 0 & 0 & 1 & 0 & 1 \\
Lethrinidae & 2 & 0 & 0 & 0 & 0 & 2 \\
Holocentridae & 1 & 0 & 2 & 0 & 0 & 2 \\
Platycephalidae & 0 & 0 & 0 & 0 & 1 & 1 \\
Diodontidae & 0 & 0 & 1 & 0 & 0 & 1 \\
Fistulariidae & 0 & 0 & 1 & 0 & 0 & 1 \\
Priacanthidae & 0 & 0 & 1 & 0 & 0 & 1 \\
& & & & & & \\
\hline
\end{tabular}

vores, as are the sea basses and wrasses in the deep reef. Therefore, it is possible that these 2 families take over the function of the damselfishes with increasing depth. The present study not only extended the known bathymetric range of many species but also, and possibly as a consequence of this, deepened the location of the richest habitat from the $5 \mathrm{~m}$ fore reef (Brokovich et al. 2006) to $30 \mathrm{~m}$, which is typically the depth limit of a majority of coral fish reef studies (Fricke \& Schumacher 1983, Colin et al. 1986, Fricke 1996, Aponte \& Ballantine 2001, Cappo et al. 2004, Feitoza et al. 2005).

Fish assemblage structure showed a gradual change in species composition along the depth gradient. Although Brokovich et al. (2006) showed a high degree of separation between assemblage composition in shallow habitats, in this study we could not distinguish between the 5 and $10 \mathrm{~m}$ (shallow) assemblages or between the 50 and $65 \mathrm{~m}$ (deep) assemblages; this could be a result of high heterogeneity or as a consequence of smaller transect sizes. The 2 shallow assemblages were grouped together on the first CAP axis and had similar species richness, similar abundance within families and relatively low species turnover. On the other hand, the 2 deep habitats, although not distinguishable in species composition, had a few separating qualities: the $65 \mathrm{~m}$ assemblage grouped well on the first CAP axis while the $50 \mathrm{~m}$ transects were more heterogenous, which suggests they differed in habitat variables. These 2 assemblages had similar species richness, which implies that the high turnover rate between them is a result of a change in species composition and not from a reduction in species number. We can also see that some of the most abundant families change in their abundance between 50 and $60 \mathrm{~m}$; mainly a reduction in Gobiidae and a rise in Ser- 
ranidae. The fish assemblage in the deeper reef changes more rapidly than in the shallow reef, and we can see it clearly with the $\beta$ diversity data. The $30 \mathrm{~m}$ depth seems to have a separate assemblage. This middle depth harbors the highest number of species, which are a combination of deep and shallow species, it has relatively high turnover with the deep assemblages and it is a mid-point for the increase in Labridae and for the decrease in Pomacentridae. This depth seems to be a transition zone between shallow and deeper assemblages, with higher similarity to the deep but with rapid species accumulation as in the shallow. It appears the $30 \mathrm{~m}$ depth is a highly heterogenic habitat. Although we have not measured any environmental variable which explains the peak in species richness at $30 \mathrm{~m}$, Loya \& Slobodkin (1971) have shown that the richest coral community lies at $30 \mathrm{~m}$. It could be argued that the rise in species richness is due to a mid domain effect (Colwell \& Lees 2000, Connolly et al. 2003, Colwell et al. 2004b, but see also Zapata et al. 2003, 2005). However, as the distribution ranges of the fish species are not constrained by the $65 \mathrm{~m}$ depth limit of the study we believe this is not the case. An examination of yet deeper habitats is needed to determine whether the transition we see in $30 \mathrm{~m}$ and possibly also in $50 \mathrm{~m}$ continues, and at which depth, if at all, the species composition will stabilize.

Although the present study shows a significant change in fish community structure over the depth gradient, it is yet to be seen if the patterns appearing in the Red Sea resemble those of other locations. This description of the fish assemblages serves as a baseline study and requires following up with studies dealing with specific species, families and functional groups to identify the main factors contributing to this change. As the deep reef has only recently begun to receive the appropriate attention, our understanding of the physical, biological and ecological processes driving its fish assemblages (as well as other taxa) is very limited and deserves further attention. Work in the deep reef will also enable us to better incorporate it into conservation plans and decision making that are aimed at protecting the structure and function of the entire reef ecosystem.

Acknowledgements. This research was supported by the Israel Science Foundation (grant no. 740/04 to S.K. and no. 550/03 to N.S.) and by the Rufford Small Grant for Nature Conservation (to E.B.). We thank O. Ben-Shaprut for his deep diving instruction and research assistance. We thank the Israel Nature and Park Authority for their cooperation. The authors are grateful to Ada Alamaru and Beverly GoodmanTchernov for reviewing this manuscript and to 3 anonymous reviewers for their insightful remarks which contributed greatly to this manuscript.

\section{LITERATURE CITED}

Anderson MJ (2002). CAP: a FORTRAN computer program for canonical analysis of principal coordinates, version 12. Department of Statistics, University of Auckland, www. stat.auckland.ac.nz/ mja/Programs.htm

Anderson MJ, Robinson J (2003) Generalized discriminant analysis based on distances. Aust NZ J Stat 45:301-318

Anderson MJ, Willis TJ (2003) Canonical analysis of principal coordinates: a useful method of constrained ordination for ecology. Ecology 84:511-525

Aponte NE, Ballantine DL (2001) Depth distribution of algal species on the deep insular fore reef at Lee Stocking Island, Bahamas. Deep-Sea Res I 48:2185-2194

Arreola-Robles JL, Elorduy-Garay JF (2002) Reef fish diversity in the region of La Paz, Baja California Sur, Mexico. Bull Mar Sci 70:1-18

Bellwood DR, Hughes TP (2001) Regional-scale assembly rules and biodiversity of coral reefs. Science 292: 1532-1535

Ben-Tuvia A, Diamant A, Baranes A, Golani D (1983) Analysis of a coral reef fish community in shallow waters of Nueiba, Gulf of Aqaba, Red Sea. Bull Inst Oceanogr Fish 9:193-206

Bortone SA, Hastings RW, Oglesby JL (1986) Quantification of reef fish assemblages: A comparison of several in situ methods. Northeast Gulf Sci 8:1-22

Brokovich E (2001) The community structure and biodiversity of reef fishes at the northern Gulf of Aqaba (Red Sea) with relation to their habitat. MSc thesis, Tel Aviv University, Israel (in Hebrew with English abstract)

Brokovich E, Baranes A (2005) Community structure and ecology of butterflyfishes (Chaetodontidae) in the Gulf of Aqaba (northern Red Sea). Aquat Conserv 15:S45-S58

- Brokovich E, Baranes A, Goren M (2006) Habitat structure determines coral reef fish assemblages at the northern tip of the Red Sea. Ecol Indic 6:494-507

Cappo M, Speare P, De'ath G (2004) Comparison of baited remote underwater video stations (BRUVS) and prawn (shrimp) trawls for assessments of fish biodiversity in interreefal areas of the Great Barrier Reef Marine Park. J Exp Mar Biol Ecol 302:123-152

Carpenter KE, Miclat RI, Albaladejo VD, Corpuz VT (1981) The influence of substrate structure on the local abundance and diversity of Philippine reef fishes. Proc 4 th Intl Coral Reef Symp, Manila 2:497-502

Chabanet P, Ralambondrainy H, Amanieu M, Faure G, Galzin R (1997) Relationships between coral reef substrata and fish. Coral Reefs 16:93-102

> Clarke KR (1993) Nonparametric multivariate analyses of changes in community structure. Aust J Ecol 18:117-143

Colin P, Devaney D, Hillis-Colinvaux L, Suchanek T, Harrison JI (1986) Geology and biological zonation of the reef slope, 50-360 m depth at Enewetak Atoll, Marshall Islands. Bull Mar Sci 38:111-128

Colwell RK (2005). EstimateS: statistical estimation of species richness and shared species from samples, version 7.5. http://purl.oclc.org/estimates

Colwell RK, Coddington JA (1994) Estimating terrestrial biodiversity through extrapolation. Phil Trans R Soc Lond B 345:101-118

Colwell RK, Lees DC (2000) The mid-domain effect: geometric constraints on the geography of species richness. Trends Ecol Evol 15:70-76

> Colwell RK, Mao CX, Chang J (2004a) Interpolating, extrapolating, and comparing incidence-based species accumulation curves. Ecology 85:2717-2727

Colwell RK, Rahbek C, Gotelli NJ (2004b) The mid-domain effect and species richness patterns: What have we learned so far? Am Nat 163:E1-E23 
Connolly SR, Bellwood DR, Hughes TP (2003) Indo-Pacific biodiversity of coral reefs: deviations from a mid-domain model. Ecology 84:2178-2190

Debelius H (1993) Indian Ocean tropical fish guide. Aquaprint Verlags GmbH, Frankfurt

Debelius H (1998) Red Sea reef guide. IKAN, Frankfurt

> Donaldson TJ (2002) Habitat association and depth distribution of 2 sympatric groupers of the genus Cephalopholis (Serranidae: Epinephelinae). Ichthyol Res 49: 191-193

Feitoza BM, Rosa RS, Rocha LA (2005) Ecology and zoogeography of deep-reef fishes in northeastern Brazil. Bull Mar Sci 76:725-742

Fishelson L (2003) Coral and fish biocoenosis: ecological cells gradually maturing in complexity, species composition and energy turnover. Environ Biol Fishes 68: 391-405

Fricke HW (1996) Deep-water exploration of the Red Sea by submersible. In: Uiblein F, Ott J, Stachowitsch M (eds) Deep-sea and extreme shallow-water habitats: affinities and adaptations. Biosyst Ecol Ser 11:67-89

Fricke HW, Schumacher H (1983) The depth limit of Red Sea stony corals: an ecophysiological problem (a deep diving survey by submersible). Mar Biol 4:163-194

Friedlander AM, Parrish JD (1998) Habitat characteristics affecting fish assemblages on a Hawaiian coral reef. J Exp Mar Biol Ecol 224:1-30

Froese R, Pauly D (eds) (2007) FishBase. www.fishbase.org

Gotelli NJ, Colwell RK (2001) Quantifying biodiversity: procedures and pitfalls in the measurement and comparison of species richness. Ecol Lett 4:379-391

Grigg WG (1994) Effects of sewage discharge, fishing pressure and habitat complexity on coral ecosystems and reef fishes in Hawaii. Mar Ecol Prog Ser 103:25-34

Jones GP, Syms C (1998) Disturbance, habitat structure and the ecology of fishes on coral reefs. Aust J Ecol 23:287-297

Khalaf MA, Disi AM (1997) Fishes of the Gulf of Aqaba. The Marine Science Station, Aqaba

Khalaf MA, Kochzius M (2002) Community structure and biogeography of shore fishes in the Gulf of Aqaba, Red Sea. Helgol Mar Res 55:252-284

Kochzius M (2003) Threatened fishes of the world: Chromis pelloura Randall \& Allen, 1982 (Pomacentridae). Environ Biol Fishes 68:142

Koleff P, Gaston KJ, Lennon JJ (2003) Measuring beta diversity for presence-absence data. J Anim Ecol 72:367-382

Lara EN, Gonzalez EA (1998) The relationship between reef fish community structure and environmental variables in the southern Mexican Caribbean. J Fish Biol 53:209-221

Lennon JJ, Koleff P, Greenwoo DJJD, Gaston KJ (2001) The geographical structure of British bird distributions: diversity, spatial turnover and scale. J Anim Ecol 70:966-979

Lewis AR (1997) Effects of experimental coral disturbance on the structure of fish communities on large patch reefs. Mar Ecol Prog Ser 161:37-50

Lieske E, Myers R (2004) Coral reef guide, Red Sea to Gulf of Aden, south Oman. HarperCollins, London

Lindell D, Post AF (1995) Ultraphytoplankton succession is triggered by deep winter mixing in the Gulf of Aqaba (Eilat), Red Sea. Limnol Oceanogr 40:1130-1141

Loya Y, Slobodkin LB (1971) The coral reefs of Eilat (Gulf of Eilat, Red Sea). Symp Zool Soc Lond 28:117-139

- Mass T, Einbinder S, Brokovich E, Shashar N, Vago R, Erez J, Dubinsky Z (2007) Photoacclimation of Stylophora pistillata to light extremes: metabolism and calcification. Mar Ecol Prog Ser 334:93-102

- McGehee MA (1994) Correspondence between assemblages of coral reef fishes and gradients of water motion, depth, and substrate size off Puerto Rico. Mar Ecol Prog Ser 105: 243-255

Editorial responsibility: John Choat,

Townsville, Queensland, Australia
Meekan MG, Steven DL, Fortin MJ (1995) Spatial patterns in the distribution of damselfishes on a fringing coral reef. Coral Reefs 14:151-161

> Mena JL, Vazquez-Dominguez E (2005) Species turnover on elevational gradients in small rodents. Global Ecol Biogeogr 14:539-547

Mergner H (1971) Structure, ecology and zonation of Red Sea reefs (in comparison with south Indians and Jamaican reefs). Symp Zool Soc Lond 28:141-161

Mora C, Chittaro PM, Sale PF, Kritzer JP, Ludsin SA (2003) Patterns and processes in reef fish diversity. Nature 421: 933-936

Nanami A, Nishihira M (2002) The structures and dynamics of fish communities in an Okinawan coral reef: effects of coral-based habitat structures at sites with rocky and sandy sea bottoms. Environ Biol Fishes 63:353-372

Ohman MC, Rajasuriya A, Ólafsson E (1997) Reef fish assemblages in north-western Sri Lanka: distribution patterns and influences of fishing practises. Environ Biol Fishes 49: $45-61$

Ormond RFG, Edwards A (1987) Red Sea fishes. In: Edwards AJ, Head SM (eds) Red Sea. Pergamon Press, Oxford, p 251-287

Pyle RL (2000) Assessing undiscovered fish biodiversity on deep coral reefs using advanced self-contained diving technology. Mar Technol Soc J 34:82-91

Randall JE (1983) Red Sea reef fishes. IMMEL Publishing, London

Randall JE (1995) Coastal fishes of Oman. Crawford House, Bathurst

Randall JE, Allen GR, Steene RC (1990) Fishes of the Great Barrier Reef and Coral Sea. University of Hawaii, Honolulu

Rickel S, Genin A (2005) Twilight transitions in coral reef fish: the input of light-induced changes in foraging behaviour. Anim Behav 70:133-144

> Rilov G, Benayahu Y (1998) Vertical artificial structures as an alternative habitat for coral reef fishes in disturbed environments. Mar Environ Res 45:431-451

> Rilov G, Benayahu Y (2000) Fish assemblage on natural versus vertical artificial reefs: the rehabilitation perspective. Mar Biol 136:931-942

Roberts CM, McClean CJ, Veron JEN, Hawkins JP and others (2002) Marine biodiversity hotspots and conservation priorities for tropical reefs. Science 295:1280-1284

> Rosenfeld M, Yam R, Shemesh A, Loya Y (2003) Implication of water depth on stable isotope composition and skeletal density banding patterns in a Porites lutea colony: results from a long-term translocation experiment. Coral Reefs $22: 337-345$

Russ GR (2003) Grazer biomass correlates more strongly with production than with biomass of algal turfs on a coral reef. Coral Reefs 22:63-67

Sheppard C, Price A, Roberts C (1992) Marine ecology of the Arabian region. Academic Press, London

Srinivasan M (2003) Depth distributions of coral reef fishes: the influence of microhabitat structure, settlement, and post-settlement processes. Oecologia 137:76-84

Wantiez L, Chauvet C (2003) First data on community structure and trophic networks of Uvea coral reef fish assemblages (Wallis and Futuna, South Pacific Ocean). Cybium $27: 83-100$

Wilson MV, Shmida A (1984) Measuring beta diversity with presence absence data. J Ecol 72:1055-1064

> Zapata FA, Gaston KJ, Chown SL (2003) Mid-domain models of species richness gradients: assumptions, methods and evidence. J Anim Ecol 72:677-690

Zapata FA, Gaston KJ, Chown SL (2005) The mid-domain effect revisited. Am Nat 166:E144-E148 